\title{
Use of Enterprise Social Software to Support Organization and People Sensemaking
}

\author{
David R. Millen \\ IBM T J Watson Research Center \\ Cambridge, Massachusetts, USA 02142 \\ david_r_millen@us.ibm.com
}

There has been considerable recent interest in the use of Web 2.0/social software in organizational settings. In this talk, several IBM research projects will be discussed in which social software was tailored for business and deployed within a large global enterprise (IBM). These projects include a social bookmarking service (dogear), a lightweight file sharing application (cattail) and a social network application (beehive). Two important research topics will be discussed. First, we explore various application capabilities that support and encourage social interaction and application adoption. Several incentive systems were tested in field trials and showed sustained increase in user participation levels. Recommender applets were also trialed to understand their ability to support the increased end-user "production" of content. The second topic will be the use of social software to promote sensemaking for people and the organization. In particular, we explore the integration of various social software applications with search tools, and the introduction of non-traditional work content (e.g., personal photos) to signal and support organizational acculturation. 